\title{
Cuidados intensivos com a pele do recém-nascido pré-termo ${ }^{1}$
}

\author{
I ntensive care with the skin of newborn pre-term
}

\section{Cuidados intensivos con la piel de los recién nacidos prematuro}

Louanna Silva de Macedo Adriano', Izaura Luzia Silvério Freire" , J uliana Teixeira Jales Menescal Pinto ${ }^{\prime \prime \prime}$

\begin{abstract}
${ }^{1}$ Artigo desenvolvido a partir da monografia apresentada a Universidade Potiguar para título de especialista em Terapia Intensiva no segundo semestre de 2007

I Enfermeira. Especialista em Terapia intensiva. Enfermeira assistencial do Bloco Cirúrgico do Hospital Regional de Guarabira e do PSF do Município de Japi - RN. Email: louannasilva@yahoo.com.br.

II Enfermeira. Mestre em Enfermagem pela Universidade Federal do Rio Grande do Norte (UFRN). Professora da Escola de Enfermagem de Natal (EEN/UFRN). Enfermeira assistencial da Unidade de Terapia Intensiva Pediátrica do Hospital Monsenhor Walfredo Gurgel. Email: izaurafreire@hotmail.com.

III Enfermeira. Mestre em Enfermagem pela UFRN. Professora da EEN/UFRN. Enfermeira assistencial do Hospital de Pediatria da UFRN. Email: jujales@hotmail.com.
\end{abstract}

\section{RESUMO}

O cuidado com a pele do Recém-Nascido Pré-termo (RNPT) é uma preocupação constante dos profissionais que trabalham em Unidade de Terapia Intensiva Neonatal (UTIN), sendo este iniciado logo após o nascimento, com a finalidade de manter uma temperatura corporal ideal e contribuir significativamente para uma adaptação bem sucedida. Objetivamos nesse estudo realizar uma atualização bibliográfica e uma análise sobre a prevenção de infecções e lesões de pele dos RNPTs e sobre os cuidados essenciais com a pele desses Recém-nascidos (RNs) internados em UTIN. Para tanto, realizamos um estudo bibliográfico, utilizando as bases de dados eletrônicas LILACS, BDENF e MEDLINE. Encontramos 222 artigos, desses, 29 tinham uma maior relevância para o nosso estudo. Dos 29 artigos, predominaram os estudos experimentais (19), no período de 1995 a 2000 (10) e os estudos bibliográficos (10) nos anos 2001 a 2006 (05). Os estudos bibliográficos, mesmo tendo um menor número de pesquisas, os autores trabalham mais categorias em um mesmo estudo (30). Os dados obtidos mostram que ainda há uma falta de consenso sobre determinadas técnicas desenvolvidas com os RNPT, apontando para a necessidade de pesquisas nessa área de assistência.

Descritores: Pele; Recém-nascido; Unidades de Terapia Intensiva Neonatal.

\section{ABSTRACT}

The care with the skin of the Pre-term Newborn Infant (PTNB) is a constant concern of professionals working in the Neonatal Intensive Care Unit (NICU), which is initiated soon after birth, with the aim of maintaining an ideal body temperature and significantly contribute to a successful adaptation. We aim in this study performing an updated literature and an analysis on the infections prevention and skin injuries on PTNBs and the essential skin care with those interned in NICUs. Thus, we performed a bibliographical review, using the electronic databases LILACS, BDENF and MEDLINE. We have found 222 articles, in which 29 had a greater relevance to our study. Of the 29 articles, had predominated experimental studies (19), in the period from 1995 to 2000 (10) and bibliographical studies (10) in the years of 2001 to 2006 (05). In bibliographical studies, even taking a smaller number of researches, the authors had studied more categories in the same study (30). The data obtained show that still there is a lack of consensus on certain techniques developed with the PTNB, pointing to the need for researches in this assistance area.

Descriptors: Skin; Infant, Newborn; Intensive Care Units; Neonatal.

\section{RESUMEN}

El cuidado con la piel del Recién Nacido Prematuro (RNPT) es una preocupación constante de los profesionales que trabajan en Unidad de Cuidados Intensivos Neonatales (UTIN), siendo éste iniciado luego después del nacimiento, con la finalidad de mantener una temperatura corporal ideal y contribuir significativamente para una adaptación bien sucedida. Buscamos en ese estudio realizar una actualización bibliográfica y un análisis sobre la prevención de infecciones y lesiones de piel de los RNPTs y sobre los cuidados esenciales con la piel de esos RNs internados en UTIN. Para eso, realizamos un estudio bibliográfico, utilizando las bases de datos electrónicos LILACS, BDENF y MEDLINE. Encontramos 222 artículos. De esos, 29 tenían una mayor relevancia para nuestro estudio. De los 29 artículos, predominaron los estudios experimentales (19), en el período de 1995 a 2000 (10) y los estudios bibliográficos (10), en los años 2001 a 2006 (05). Los estudios bibliográficos, igualmente teniendo un menor número de investigaciones, los autores trabajan más categorías en un mismo estudio (30). Los datos obtenidos muestran que todavía hay una falta de consenso sobre determinadas técnicas desenvueltas con los RNPT, señalando para la necesidad de Investigaciones en esa área de asistencia.

Descriptors: La piel; Recién nacido; Unidades de Terapia Intensiva Neonatal. 


\section{NTRODUÇÃO}

O cuidado com a pele do Recém-nascido Prétermo (RNPT) é uma preocupação constante dos profissionais que trabalham em Unidade de Terapia Intensiva Neonatal (UTIN), sendo este iniciado logo após o nascimento, com a finalidade de manter uma temperatura corporal ideal e contribuir significativamente para uma adaptação bem sucedida.

A pele atua como uma interface entre o meio interno e externo, sua função primária é a proteção, sendo esta limitada no RNPT, isto porque a camada de estrato córneo não está desenvolvida, propiciando um conseqüente risco de instabilidade térmica como resultado da maior perda de calor por evaporação, aumento das necessidades de água e dos riscos de absorção transdérmica de substâncias aplicadas, colonização e infecção invasiva ${ }^{(1)}$.

Cerca de $80 \%$ dos recém-nascidos (RNs) que nascem prematuramente desenvolvem alguma injúria na pele até o primeiro mês de vida e aproximadamente $25 \%$ de todos os pré-termos e de baixo peso, terão ao menos um episódio de sepse até o 3 o dia de vida, sendo a pele a principal porta de entrada(2).

No mundo, aproximadamente 350.000 RNPT morrem em função de sepse e meningite, sendo $50 \%$ dos óbitos na primeira semana de vida, quando a função de barreira da epiderme encontra-se mais comprometida. Esses números são ainda maiores nos países em desenvolvimento, atingindo índices de mortalidade até $70 \%{ }^{(1)}$.

Considerando todos esses aspectos, identificamos que a profilaxia dessas lesões deve-se em grande parte à equipe que cuida do paciente, em especial a de enfermagem, que responde por vários mecanismos de prevenção, seja em atividades administrativas, de supervisão e de treinamento de pessoal, seja nos cuidados prestados aos RNs admitidos na UTIN.

Com esse propósito, o papel do enfermeiro na UTIN é fundamental, uma vez que ele se dedica ao paciente durante as 24 horas do dia, exercendo funções específicas na adaptação do RN à vida extrauterina por meio da manutenção do equilíbrio térmico, quantidade de umidade, luz, som e estímulo cutâneo adequado. De igual forma é fundamental a observação constante do quadro clínico, através do exame físico, monitorização dos sinais vitais e emprego de procedimentos de assistência especial, administração da alimentação adequada para suprir as necessidades metabólicas dos sistemas orgânicos em desenvolvimento, se possível auxiliando e orientando a mãe para o aleitamento materno. Outras atribuições importantes desse profissional é o controle de infecções, a educação dos pais e familiares, a administração, coordenação, ensino e a supervisão dos cuidados de enfermagem prestados ${ }^{(3)}$.
Nesse sentido, afirmamos que, por causa da maior sensibilidade e fragilidade, os cuidados com a pele do RNPT têm como objetivos a serem alcançados, a manutenção da integridade da pele, prevenção de injúria física, química e de infecções, diminuição da perda insensível de água, estabilidade da temperatura e proteção da absorção de agentes tópicos(2).

Sabemos que o cuidado com esses RNs impõem um desafio quase que intransponível: a missão de devolver às famílias e à sociedade o recém-nascido capaz de desenvolver de maneira plena o seu potencial afetivo, cognitivo e produtivo. A imprecisão sobre até onde os esforços dos profissionais que trabalham nessa área podem e devem se concentrar para manter a vida de nossos pequenos pacientes é um dos terrenos escorregadios mais difíceis para se tomarem as decisões corretas.

Após uma minuciosa consulta à literatura, associada a nossa experiência profissional como enfermeira assistencial de uma UTIN de um Hospital Público do interior do Rio Grande do Norte há três anos, observamos que as lesões de pele em RNPT é um problema de extrema relevância. Isso se deve ao grande número de ocorrência dessa afecção nessa unidade de internamento, apesar da inexistência de dados estatísticos que substanciem tais afirmações. Vimos, também, que a adoção de protocolos assistenciais, baseados em estudos atuais, constitui uma importante medida na uniformização de condutas, e com isso diminuiu os riscos de aparecimento dessas lesões.

Diante desse contexto, sentimos a necessidade de realizar um estudo bibliográfico que versasse sobre as medidas preventivas e os cuidados com a pele do RNPT. Para, dessa forma, podermos oferecer informações teórico-práticos que enriqueçam, ainda mais, a experiência cotidiana dos enfermeiros que atuam nessa área de assistência.

Baseadas no pressuposto de que o cuidado adequado com a pele do RNPT, internado na UTIN, reduz o risco de complicações, questionamos: quais são os cuidados e as medidas preventivas utilizadas para diminuir o aparecimento de lesões e infecções de pele ocorridas no RNPT numa UTIN, encontradas na literatura?

Considerando este questionamento, conhecendo a realidade exposta e a importância desse assunto, objetivamos nesse estudo realizar uma atualização bibliográfica e uma análise sobre a prevenção de infecções e lesões de pele dos RNPTs e sobre os cuidados essenciais com a pele desses RNs internados em UTIN. Ao realizarmos essa pesquisa, esperamos que os resultados venham subsidiar os profissionais que atuam junto aos RNPT para que possam intervir positivamente na prevenção e reabilitação das complicações e seqüelas desses recém-nascidos. 


\section{METODOLOGI A}

A pesquisa é do tipo bibliográfica, realizada em bases de dados eletrônicas. A coleta de dados foi realizada durante os meses de janeiro a setembro de 2008, fazendo um vasto levantamento bibliográfico nas bases de dados eletrônicas da Literatura LatinoAmericana e do Caribe em Ciências da Saúde (LILACS), Base de Dados de Enfermagem (BDENF) e Literatura Internacional em Ciências da Saúde (MEDLINE), consultados através do site da Biblioteca Virtual em Saúde (BVS) e da Biblioteca Regional de Medicina (BIREME).

Para a pesquisa dos artigos científicos, utilizamos dois descritores relacionados pele $X$ Recém-Nascido Prematuro. Foram encontrados 222 artigos, sendo selecionados aqueles que apresentaram uma maior relevância para a temática em estudo. Assim, fizeram parte da pesquisa 29 artigos, que posteriormente foram categorizados com base na análise de conteúdo, segundo $\operatorname{Bardin}^{(4)}$ :

- Pré-análise: a partir do material coletado, foram elaborados os indicadores de avaliação que orientaram a interpretação final do trabalho. Nessa fase foram efetuadas leituras exaustivas, visando à familiarização com o material e à sua organização, estabelecendo algumas normas de validade, como representatividade, homogeneidade e pertinência;

- Exploração do material: consistiram na codificação, agregação e escolha das categorias. Nesse momento, distribuímos os artigos em cinco categorias gerais: Cuidados com o banho, Cuidado com a pele para procedimentos invasivos, Cuidados com o cordão umbilical e Prevenção das infecções e lesões de pele, e, de cada categoria, construímos as subcategorias. E, a partir de cada categoria, construímos as subcategorias;

- Interpretação dos resultados: procuramos os significados das categorias e subcategorias estabelecidas.

Os dados foram analisados e apresentados em tabelas e quadros. Os artigos foram divididos de acordo com as categorias e subcategorias previamente determinadas. Para tanto, utilizamos a estatística descritiva e o software Microsoft-Excel XP.

\section{RESULTADOS E DISCUSSÕES}

\section{Apresentação dos 29 artigos, encontrados nos bancos de dados eletrônicos, relacionados com o cuidado com a pele do recém-nascido pré- termo.}

Nesse primeiro momento faremos uma apresentação dos 29 artigos, segundo o tipo de pesquisa e ano de publicação, de acordo com as cinco categorias encontradas: Cuidados com o banho, Cuidado com a pele para procedimentos invasivos, Cuidados com o cordão umbilical e Prevenção das infecções e lesões de pele (Quadro 1).

Quadro 1: Distribuição dos artigos de acordo com o tipo de estudo e ano de publicação. Natal, 2008.

\begin{tabular}{|l|c|c|c|c|c|c|}
\hline \multicolumn{1}{|c|}{ CATEGORI AS } & \multicolumn{7}{c|}{ ANO } \\
\cline { 2 - 6 } & $\mathbf{8 3 - 8 8}$ & $\mathbf{8 9 - 9 4}$ & $\mathbf{9 5 - 0 0}$ & $\mathbf{0 1 - 0 6}$ & $\mathbf{> 0 7}$ & TOTAL \\
\hline Estudos Experimentais & - & - & $\mathbf{1 0}$ & $\mathbf{0 8}$ & $\mathbf{0 1}$ & $\mathbf{1 9}$ \\
\hline Banho & - & - & 04 & 02 & - & 06 \\
\hline Cuidados com procedimentos invasivos & - & - & 02 & - & - & 02 \\
\hline Cuidados com o cordão umbilical & - & - & 01 & - & - & 01 \\
\hline Cuidados com os emolientes & - & - & 03 & 01 & 01 & 05 \\
\hline Prevenção das infecções e lesões da pele & - & 01 & 06 & 03 & - & 10 \\
\hline TOTAL & - & $\mathbf{0 1}$ & $\mathbf{1 6}$ & $\mathbf{0 6}$ & $\mathbf{0 1}$ & $\mathbf{2 4}$ \\
\hline Estudos Bibliográficos & $\mathbf{0 3}$ & - & $\mathbf{0 2}$ & $\mathbf{0 5}$ & - & $\mathbf{1 0}$ \\
\hline Banho & 02 & - & - & 04 & - & 06 \\
\hline Cuidados com a pele para procedimentos invasivos & 01 & - & - & 02 & - & 03 \\
\hline Cuidados com o cordão umbilical & 01 & - & - & 01 & - & 02 \\
\hline Cuidados com os emolientes & 01 & - & 01 & 05 & - & 07 \\
\hline Prevenção das infecções e lesões da pele & 03 & - & 02 & 07 & - & 12 \\
\hline TOTAL & $\mathbf{0 8}$ & - & $\mathbf{0 3}$ & $\mathbf{1 9}$ & - & $\mathbf{3 0}$ \\
\hline
\end{tabular}

No Quadro 1, detectamos os 29 artigos relevantes para o estudo e sua divisão quanto ao ano de publicação, tipo de estudo e categorias trabalhadas. Ressaltamos que em um mesmo artigo encontramos uma ou mais categorias. Vimos que houve uma maior predominância dos estudos experimentais (19), e que esse tipo de estudo teve uma maior ênfase a partir dos anos 1995 a 2000
(10). Este fato também pode ser observado na categoria prevenção das infecções e lesões de pele, que teve um maior número de estudos (10), notadamente, nos referidos anos.

Quanto aos estudos bibliográficos, evidenciamos um maior destaque para os anos 2001 a 2006 (05), seguidos dos anos 1993 a 1988 (03). Neste, mesmo aparecendo um menor número de artigos (10), os 
autores trabalhavam mais categorias em uma mesma pesquisa (30). A categoria que mais se destacou foi a prevenção das infecções e lesões de pele (12), seguidos dos cuidados com os emolientes (07) e cuidados com o banho (06).

\section{Cuidados relacionados com a pele do RNPT, segundo as categorias e subcategorias encontradas nos $\mathbf{2 8}$ artigos.}

Após leitura exaustiva e atenciosa, distribuímos os 29 artigos em cinco categorias, como já foi mostrado anteriormente (Quadro 1), depois analisamos cada categoria de acordo com a citação em cada artigo e construímos as subcategorias:

- Cuidados com o banho: nessa categoria, foram encontradas 03 sub-categorias: banho somente com água ou com o uso de sabonetes; banho diário e adiar o primeiro banho.

- Cuidado com a pele para procedimentos invasivos: em relação a este cuidado foram encontrados 05 tipos de procedimentos: Uso do álcool a $70 \%$, seguida do álcool isopropril a $70 \%$, Clorexidina a $0,5 \%$, Clorexidina a $0,5 \%$ com álcool isopropril a $70 \%$, Povidineiodo a $10 \%$.

- Cuidados com o cordão umbilical: em relação a esta categoria ela se subdivide em Curativo diário, Uso de clorexidine e Uso de álcool a $70 \%$.

- Cuidados com os emolientes: sobre este cuidado foi pesquisado o uso ou não de emolientes no RNPT.

- Prevenção de infecções e lesões de pele: Nesta categoria foram encontrados os seguintes cuidados: Lavagem das mãos, Uso de Equipamentos de Proteção Individuais (EPIs), Limpeza e desinfecção dos equipamentos, Mudança de decúbito, Uso de adesivos, Uso de eletrodos para Eletrocardiograma (ECG), Plásticos de polietileno elásticos, Uso de tintura de benjoim, Aplicação de solventes para remoção de adesivos, Uso de curativos transparentes e Estratégias para a diminuição da perda de água e calor.

\section{Cuidados com o banho}

Identificamos que havia uma mesma quantidade de artigos (06) que abordavam sobre o banho somente com água ou com o uso de sabonetes.

É enfatizado que o primeiro banho do RN deve ser realizado somente com água, deixando o vérnix para que seja absorvida naturalmente, e que deve continuar banhando o bebê somente com água morna até as primeiras 2 a 4 semanas e, então, gradualmente vai introduzindo sabonete em quantidades minúsculas. Afirma, ainda, que este produto pode ser utilizado de duas a três vezes durante a semana, deve ter o pH neutro, não conter tintura e nem perfume. Já em pré-termos nascidos com idade gestacional inferior a 32 semanas, recomenda a utilização de água esterilizada morna para a remoção dos fluidos corporais, pois esta não altera a flora da pele, e em pré-termo com menos de 26 semanas de idade gestacional, a utilização de água esterilizada é fundamental ${ }^{(5)}$.

O uso de sabonete e degermante são questionados na literatura quando se refere ao RNPT. O uso freqüente desses produtos tem por finalidade remover a sujeira, no entanto, retira o filme lipídico da superfície da pele, causando irritação. Salientam, ainda, que o banho com sabonete desencadeia um aumento no $\mathrm{pH}$ da pele que interfere na proteção fisiológica, provocando mudança na composição da flora bacteriana cutânea e na atividade das enzimas da epiderme. Outra conseqüência é a dissolução da gordura da superfície da epiderme, influenciando nas condições de hidratação e predispondo o RN à secura e à descamação da pele $\mathrm{e}^{(6-7)}$.

Apesar do uso de agentes tópicos, como sabonetes, xampus e degermantes, serem questionados na literatura, na prática o uso desses produtos ainda são muito freqüentes, como podemos constatar em um estudo realizado em UTINs de 139 hospitais americanos sobre os procedimentos no cuidado com a pele. O resultado mostrou que, em $51 \%$ das unidades avaliadas, os recém-nascidos prétermo de baixo peso ao nascer eram rotineiramente banhados. Dessas unidades, $15 \%$ utilizavam somente água e $85 \%$ faziam uso de algum tipo de produto de limpeza. Em cerca de $75 \%$ das unidades, usavam-se preferencialmente produtos de limpeza líquidos, como os xampus ou banhos líquidos para bebê. Nos demais locais ( $25 \%$ ), era usado algum tipo de sabonete comercial em barra ${ }^{(8)}$.

Quanto ao banho diário, vimos em 03 artigos, que este altera $\mathrm{o} \mathrm{pH}$ da pele, não permitindo a formação do manto ácido e facilitando a colonização bacteriana ${ }^{(9-11)}$.

Em investigação realizada pela Universidade da Califórnia numa UTIN com RNPT, foi observada uma freqüência de banho de quatro em quatro dias com água e sabonete Neutrogena, e realizado coletas de culturas da pele dos prematuros em períodos de 30 minutos, 48 horas, 72 horas e 96 horas após o banho. Os resultados sugeriram que essa freqüência não aumenta o risco para infecção ${ }^{(12)}$.

No município de São Paulo, em uma UTIN de um hospital escola, o banho é realizado uma vez por semana em neonatos submetidos à ventilação mecânica ou na urgência de desconforto respiratório e naqueles com peso inferior a $1000 \mathrm{~g}$, utilizando-se apenas bolas de algodão e água morna. São realizados 2 a 3 vezes por semana em neonatos sem 
distúrbios respiratórios com peso superior a $1000 \mathrm{~g}$, onde evidenciou uma boa evolução clínica do $\mathrm{RN}^{(9)}$.

Com relação à subcategoria adiar o primeiro banho, foram encontrados 02 artigos. O primeiro estudo mostra o posicionamento de dois autores. Um autor orienta que o banho no RN, com idade gestacional a partir de 38 semanas, peso adequado e índice de apgar no quinto minuto de maior que 7 , deverá ser realizado quando a temperatura axilar for igual ou maior de $36,8^{\circ} \mathrm{C}$, já o segundo recomenda que o banho deverá ser retardado por sete horas para que os sinais vitais estejam estáveis ${ }^{(6)}$.

Quanto ao segundo artigo, este relata que o primeiro banho do RN poderá ser dado após a estabilização da temperatura por duas a quatro horas $^{(5)}$.

\section{Cuidado com a pele para procedimentos invasivos}

$\mathrm{Na}$ categoria cuidados com a pele para procedimentos invasivos, pesquisamos as soluções que devem ou não ser utilizadas na preparação da pele, e observamos que a mais citada foi o álcool a $70 \%$ (03), seguida do álcool isopropril a 70\% (02).

Essas soluções geralmente são empregadas na preparação da pele antes de procedimentos invasivos, entretanto, não são seguras. Em recémnascidos, a aplicação de anti-sépticos que contenham álcool a $70 \%$ ou álcool isopropril a $70 \%$ pode causar lesões iatrogênicas na pele, incluindo queimaduras e lesões cáusticas ${ }^{(9,13-15)}$

O álcool a 70\% não é recomendado nem para o preparo inicial da pele e nem para remoção da clorexidine, devido a sua possível absorção, além de não ter impedido epidemias recorrentes de infecção estreptocócica $^{(14)}$.

Apesar de antigos relatórios mostrarem que os anti-sépticos associados com álcool a 70\%, como gluconato e clorexidine a $0,5 \%$ serem extensamente usados com grande efetividade na esterilização da pele dos neonatos antes da inserção de linhas percutâneas centrais e umbilicais, a literatura descreve dois casos de bebês nascidos de uma gestação de 24 semanas que desenvolveram extensivas queimaduras no abdome com clorexidine alcoólica aplicada antes da inserção de catéteres umbilicais. Essas queimaduras severas podem causar despigmentação da pele, hipotermia, perda de água excessiva, sepse, e falha renal, causando, adicionalmente, dor, stress e afetando a maturação do tecido cerebral ${ }^{(16)}$.

Quanto ao Polivinilpirolidona (PVPI) é relatado que essa substância pode ser absorvida pela pele, permanecendo na corrente sanguínea por períodos prolongados, devido à imaturidade dos órgãos excretores, aumentando os riscos de toxicidade e causando hipotireidismo ${ }^{(14)}$.

Para o sistemático dessa substância, deve-se utilizar gaze embebida nesse anti-séptico e aplicada na pele por contato suave para evitar a remoção mecânica das camadas superficiais da epiderme, e o excesso é removido com algodão embebido em água destilada no final do procedimento ${ }^{(9)}$.

Quanto a clorexidine a 0,5\% apesar de ser uma das menos citadas (01), é ressaltado que seu uso é mais eficiente do que o PVPI na redução do risco de colonização por cateter periférico, podendo ocorrer absorção sistêmica na sua forma alcoólica. A clorexidine a $0,5 \%$ isolada é mais a recomendada e segura entre todos os anti-sépticos ${ }^{(6)}$.

\section{Cuidados com o cordão umbilical}

Quanto à categoria cuidados com o cordão umbilical, observamos que os artigos recomendam que o primeiro curativo umbilical deva ser realizado empregando-se gaze esterilizada embebida em solução alcoólica de clorexidine aplicada somente no local, evitando que o produto escorra na pele do neonato. Orienta, ainda, que este curativo seja realizado três vezes ao dia ${ }^{(9)}$.

No que se refere aos cuidados para acelerar o processo de cicatrização e queda do coto umbilical, a literatura recomenda uma boa higienização, curativo diário, limpeza e anti-sepsia do local onde o coto se insere e área sempre arejada e seca ${ }^{(14)}$.

No que se refere à solução utilizada para o curativo umbilical, a clorexidine a $0,5 \%$ mostra ser superior ao álcool a 70\%, por ter menor toxicidade e maior eficácia em reduzir colonização por Streptococos grupo A e Staphilococos aureus, ou seja, oferece uma antissepsia mais eficaz, com menos efeitos colaterais ${ }^{(9)}$.

No Brasil, apesar dos efeitos colaterais do álcool a $70 \%$, este produto ainda continua sendo recomendado, por ter um menor custo e uma ação imediata $^{(6)}$.

\section{Cuidados com os emolientes}

Nesta categoria, identificamos que 12 artigos tratavam da aplicação ou não de emolientes em recém nascidos. Destes, 09 relatam que os emolientes funcionam na prevenção da ruptura da barreira cutânea e penetração de bactérias e 03 afirmam que essas substâncias trazem alguns efeitos benéficos, mas predispõe o RN a infecções.

O uso de emolientes, como óleos a base de petrolato, girassol e canola têm aumentado na rotina das UTIN desde um estudo piloto da Stanford University. Este estudo recomenda a aplicação de emolientes na pele do recém-nascido pré-termo, abaixo de 33 semanas, duas vezes ao dia nas primeiras duas semanas de vida e conclui que estes neonatos apresentaram menos episódios de piora clínica por sepse e menor incidência de meningite quando comparado com o grupo controle $e^{(17)}$.

Quando o RN encontra-se em uso de calor radiante e incubadora é necessária a aplicação de 
emolientes. O uso de emoliente a base de petrolato, óleo e cera mineral e lanolina, pode diminuir a secura, melhorar as condições da pele, manter a sua função de barreira e reduzir a incidência de sérias infecções ${ }^{(6,18)}$.

Em estudo realizado com esse produto em RNs de peso baixíssimo, mostraram que os RNs tiveram uma significante melhora na contagem de colônias e condição de pele em relação aos não tratados, que piorou antes e durante o tratamento. Portanto, nessa investigação, concluiu que o uso do emoliente, usado durante as primeiras semanas pós-natal, melhora as condições de pele do RN com idade gestacional de 26 a 30 semanas, sem mudar a contagem de bactérias da pele(18).

Entretanto, apesar do uso dos emolientes melhorarem as condições cutâneas e prevenir perda de água por essa via nos primeiros 15 dias, não há evidências de proteção contra a invasão bacteriana. Contrariamente, uma pesquisa que incluiu 1.191 recém-nascidos de peso ao nascer entre 501 e $1.000 \mathrm{~g}$ e idade gestacional $\leq 32$ semanas, alocados para receber aplicação generalizada de emolientes duas vezes ao dia ou aplicação seletiva no local da lesão cutânea, ao invés de demonstrar efeito protetor contra a infecção, detectou maior risco de sepse bacteriana hospitalar. Semelhantemente, recente metanálise dos estudos disponíveis na literatura também mostrou que a aplicação profilática de emoliente tópico em pré-termos extremos aumentou o risco de ocorrência de qualquer infecção nosocomial e, principalmente, de infecção causada por estafilococos coagulase-negativo. Conseqüentemente, tem sido proposto o uso de forma terapêutica, somente nos locais em que haja lesões cutâneas. Entretanto, ainda não há estudos que validem a eficácia desse uso(17).

Não há um consenso sobre o uso de emolientes, mas afirmam que a maioria utiliza algum produto na prevenção de lesões cutâneas, não sendo padronizado um tipo específico ${ }^{(14)}$.

\section{Prevenção de infecções e lesões de pele}

Nesta categoria, observamos uma maior ocorrência de citações sobre o uso de adesivos (08) e das estratégias para a diminuição da perda de água e calor (08).

Os adesivos utilizados em terapia intensiva neonatal para fixar materiais como cateter venoso, tubo endotraqueal e outros podem aderir-se fortemente à pele, chegando a arrancar as camadas superficiais ou mesmo toda a epiderme ao serem removidos $^{(8)}$.

Para prevenir as perdas de água e calor, o RNPT deve ser mantido em incubadora com parede dupla, controlando a umidade ambiental e utilizando dispositivos de servo-controle, aplicar emolientes na pele a base de petrolato, cobrir a pele com manta plástica, usar cobertura transparente e envolvê-lo com plástico aerado e promover contato pele a pele (método canguru) ${ }^{(6,14,19)}$.

Quanto ao uso de eletrodos cardíacos (03), alguns autores recomendam que sejam de resina vegetal, pois estes diminuem as lesões de pele, por serem de fácil remoção, não causarem dor, nem lesarem a pele, além de possuírem tamanho menor que os convencionais ${ }^{(6,9,19)}$.

Sobre a limpeza e desinfecção dos equipamentos utilizados pelo RN, foram encontrados dois artigos que orientam a proceder à lavagem diária dos equipamentos com água e sabão ou solução antiséptica, enxugando-os com pano seco. Após a alta do RN, deve fazer a limpeza terminal de todos os equipamentos utilizados, desmontando-os, se possível, e lavando-os com água e sabão ou solução anti-séptica. No caso da incubadora, deve deixar arejar durante 6 horas, antes de prepará-la para a nova admissão e, se possível, trocar o RN desse equipamento a cada 15 dias, para a limpeza terminal. O filtro deve ser trocado uma vez por mês ou mais, se necessário. Nunca deve ser utilizado éter para a limpeza dos equipamentos, principalmente da incubadora, ou para qualquer cuidado administrado à criança, pois este é combinado com o oxigênio, sendo explosivo e tóxico. No caso de ser usada água destilada para umidificação do ambiente, trocá-la a cada 24 horas $^{(10)}$.

A mudança de decúbito, encontrada em 02 artigos, é extremamente necessária, devido à pobreza do tecido subcutâneo e muscular, e a sensibilidade da pele do RNPT. É importante, também, para evitar úlceras de decúbito, o uso de colchões de água suavemente balançados, para induzir o repouso e proteger a pele do RN e o colchão de pele de cordeiro, sintética, que, por ser macio, previne as rupturas da pele, cuidando das áreas susceptíveis $^{(6,20)}$.

A aplicação de solventes para remoção de adesivos (02) deve ser restrita porque, além de ressecar, são facilmente absorvidos pela pele, e, quando utilizados, devem ser retirados, a seguir, com água. As estratégias protetoras para o uso de adesivos incluem a sua remoção cuidadosa e paciente com água morna e sabonete neutro ${ }^{(9,20)}$.

No tocante ao uso dos EPIs (01), até pouco tempo, as UTI neonatais viviam situações totalmente paradoxais. Realizavam-se medidas rigorosas, muitas delas folclóricas, para impedir a entrada de germes comunitários, numa colonização natural do recém nascido, porém pouco era feito em termos de infecções cruzadas intra-hospitalares. Todos tinham que colocar aventais e até propés, atividade muitas vezes realizada carregando o recém nascido, favorecendo acidentes ou a própria contaminação do paciente com germes do solo, via mãos que se sujavam ao encostar-se à sola do sapato. Enquanto 
isso, dentro da unidade, a única pia era utilizada preferentemente para o banho dos recém nascidos, favorecendo a contaminação cruzada durante o atendimento. O avental era mantido enquanto o funcionário estivesse na unidade, independente da sua tarefa ou mesmo sujidade ${ }^{(12)}$.

O avental, assim como as luvas, deve ser empregado de acordo com as regras das precauções padrão, ou seja, risco de contaminação (contato com sangue ou fluídos biológicos) da roupa ou mãos, e serem removidos tão logo a atividade de risco seja concluída. O propé, obviamente, foi abolido, e os resultados são bem melhores ${ }^{(12)}$.

No que se refere ao plástico de polietileno elástico (01), é um curativo adesivo transparente que é utilizado em todos os RNs internados na UTIN. Servindo para fixar os eletrodos, talas e sensores de oxímetros e visa prevenir o aparecimento de lesões na pele. É aplicado diretamente na pele limpa e seca servindo de base para a fixação de sondas, de dispositivos para infusão venosa, de máscaras de fototerapia e de outros materiais com o esparadrapo. Este plástico se interpõe entre a pele e o esparadrapo, evitando o contato direto com a pele.

A lavagem das mãos (03) deve ser um hábito entre todos os profissionais de saúde e a adesão a esta prática é um desafio para a equipe de controle de infecção de cada hospital. A higienização básica das mãos com água e sabão visa remover a maioria dos microrganismos da flora transitória, células descamativas, suor, sujidade, oleosidades e outros fluidos, prevenindo o aumento dos índices de infecções transmitidas por contato manual direto entre RN na UTIN ${ }^{(15-19)}$.

Um ponto importante a ser observado na eficácia da prática de lavagem das mãos é o tempo gasto e a técnica utilizada no decorrer do horário de trabalho assistencial com o paciente. Outro aspecto significativo que merece ser destacado é a freqüência e o produto usado na lavagem, que podem conduzir ao ressecamento, rachaduras, dermatites e outras lesões, aumentando a probabilidade de colonização das mãos por patógenos potenciais e elevando, por conseqüência, o risco de infecção cruzada no ambiente hospitalar. As mãos devem ser lavadas antes e após todo e qualquer procedimento.

Hoje temos uma abordagem bem distinta sobre a lavagem das mãos. Esse procedimento é recomendado ao entrar na unidade e entre os procedimentos, sendo que nesta última situação pode-se empregar também o álcool gel ${ }^{(12)}$.

Os curativos transparentes de plásticos de poliuretano, hidrogel ou hidrocolóide (01) sejam usados para proteção de traumas, fixação de dispositivos e tratamento de feridas ${ }^{(6)}$.

O uso da tintura de benjoim (01) deve ser limitado, por resultar em adesões muito fortes, favorecendo a formação de lesão na pele por ocasião da remoção do adesivo, além de conter diferentes ácidos os quais absorvidos pela pele podem causar reação imediata ou $\operatorname{tardia}^{(9)}$.

\section{CONCLUSÕES}

Esse estudo possibilitou a efetivação de uma atualização bibliográfica e uma análise sobre a prevenção de infecções e lesões de pele dos RNPTs e os cuidados essenciais com a pele desses RNs internados em UTIN.

Considerando os resultados obtidos nos 28 artigos selecionados, verificamos uma maior predominância dos estudos experimentais (18), com uma maior ênfase nos anos 1995 a 2000 (10), seguidos dos estudos bibliográficos (10) destacando os anos 2001 a 2006 (05). Quanto às categorias pesquisadas prevaleceram a prevenção das infecções e lesões de pele (22).

$\mathrm{Na}$ categoria banho, observamos que das subcategorias pesquisadas havia uma mesma quantidade de artigos (06) que abordavam sobre o tema "banho somente com água" ou "banho com o uso de sabonetes". Alguns autores recomendam o banho diário (03) e orienta que o primeiro banho deva ser retardado até que os sinais vitais tornem-se estáveis.

Em relação aos cuidados com a pele para procedimentos invasivos, relacionado às soluções utilizadas, foi citado o álcool a 70\% (03), seguido do álcool isopropril a 70\% (02), como soluções que não devem ser utilizadas por não serem seguras, podendo causar lesões iatrogênicas na pele, incluindo queimaduras e lesões cáusticas. Quanto ao povidineiodo (01) verificamos que este poderá ser absorvido pela pele, aumentando os riscos de toxicidade e causando hipotireoidismo. A clorexidine a $0,5 \%$ é citada como a solução que causa menos danos ao RNPT, no entanto, é a menos citada nos estudos.

Quanto aos cuidados com o cordão umbilical (03), os autores recomendam curativo diário (01), com solução anti-séptica de clorexidine a 0,5\% (01) no local de inserção do coto na pele.

O uso de emolientes no RNPT foi abordado em 11 referências, que recomendaram sua utilização (08) para prevenção da ruptura da barreira cutânea e na penetração de bactérias.

Dos estudos selecionados, 22 tratam da prevenção de infecção e lesões de pele. Citam recomendações para o uso restrito de adesivos (08), as estratégias para a diminuição da perda de água e calor (08), a importância da lavagem das mãos antes e após os procedimentos (03), o uso de eletrodos cardíacos de resina vegetal (03), a limpeza e desinfecção dos equipamentos (02), a mudança de decúbito (02), a não utilização de solventes para remoção de adesivos (02), o uso de EPIs (01), uso de plástico polietileno elástico para fixar eletrodos, talas e sensores de oxímetros (01), uso limitado de 
tintura de benjoim (01) e uso de curativos transparentes de plásticos de poliuretano, hidrogel ou hidrocolóide (01) para proteção de traumas, fixação de dispositivos e tratamento de feridas.

Sabemos que inúmeros fatores podem contribuir para se evitar agravos à pele do RNPT, como vimos na literatura. Porém, nossos resultados indicam que ainda há uma falta considerável de consenso sobre determinadas técnicas, apontando para a necessidade de serem realizadas discussões sobre essa temática e estudos nessa área de assistência.

\section{REFERÊNCI AS}

1. Hahn LP. Pele do recém-nascido prematuro [monograph]. Curitiba: Departamento de Pediatria, Hospital de Clínicas da Universidade Federal do Paraná; 2001. 145p.

2. Tamez RN, Silva MJP. Enfermagem na UTI neonatal: Assistência ao recém-nascido de alto risco. 2nd ed. Rio de Janeiro: Guanabara Koogan; 1999.

3. Santos RRR, Cardoso MVLML, Silva GRFS, Lúcio IML. Aplicação de manual educativo sobre a pele do recém-nascido com estudantes de enfermagem. Rev. Eletr. Enf. [Internet]. 2007 [cited 2009 feb 12];9(3):759-71. Available from: http://www.fen.ufg.br/revista/v9/n3/v9n3a15. htm.

4. Bardin L. Análise de conteúdo. 3rd ed. Lisboa: Edições 70; 2004.

5. Irving V. Caring for and protecting the skin of preterm neonates. Journal Wound Care. 2001; 7(10): 253-56.

6. Cunha MLC, Mendes ENW, Bonilha ALL. O cuidado com a pele do recém-nascido. Rev. gaúcha enferm. 2002; 23(2): 6-15.

7. Munson KA, Bare DE, Hoath SB, Visscher MO. A survey of skin care practices for premature low birth weight infants. Neonatal Network. 1999; 18(3):25-31. 8. Ikezawa MK. Prevenção de lesões na pele de recém-nascido com peso inferior a $2000 \mathrm{~g}$ assistido em unidade neonatal: estudo experimental [thesis]. São Paulo: Escola Paulista de Medicina - Universidade Federal de São Paulo; 1998.

9. Merighi MAB. Assistência de enfermagem ao prematuro: alguns procedimentos básicos. Rev. esc. enferm. USP. 1985; 19(3):231-37.

10. Franck LS, Quinn D, Zahr L. Effect of less frequent bathing of preterm infants on skin flora and pathogen colonization. J Obstet Gynecol Neonatal Nurs. 2000; 9(6): 584-89.

11. Quinn D, Newton N, Piecuch R. Effect of less frequent bathing on premature infant skin. J Obstet Gynecol Neonatal Nurs. 2005;34(6):741-46.

12. Varda KE, Behnke R. The effect of timing of initial bath on newborn's temperature. J Obstet Gynecol Neonatal Nurs. 2000; 29(1):27-32.

13. Darmstadt GL, Dinulos JG. Neonatal skin care.

Pediatr Clin North Am. 2000;47(4): 757-82.
14. Baker SF, Smith BJ, Donohue PK, Gleason CA. Skin care management practices for premature infants. J Perinatol. 1999; 19(6 Pt 1):426-31.

15. Brayer C, Micheau P, Bony C, Tauzin L, Pilorget $\mathrm{H}$, Sampériz S, et al. Neonatal accidental burn by isopropyl alcohol. Arch Pediatr. 2004; 11(8): 932-35.

16. Reynolds PR, Banerjee S, Meek JH. Alcohol burns in extremely low birthweight infants: still occurring. Arch Dis Child Fetal Neonatal Ed. 2005;90(1): F10.

17. Mussi P, Marisa M, Rego MAC. Particularidades imunológicas do pré-termo extremo: um desafio para a prevenção da sepse hospitalar. J. Pediatr. (Rio J.) 2005; 81 Suppl 1:S59-68.

18. Darmstadt GL, Saha SK, Ahmed AS, Choi Y, Chowdhury MA, Islam $M$, et al. Effects of topical emollient treatment of preterm neonates in Blangladesh on invasion of pathogens into the bloodstream. Pediatr Res. 2007;61(5):588-93.

19. Pabst RC, Starr KP, Qaiyumi S, Schwalbe RS, Gewolb IH. The effect of application of aquaphor on skin condition, fluid requirements, and bacterial colonization in very low birth weight infants. J Perinatol. 1999; 19(4): 278-83.

20. Da Poian VRL. Alguns aspectos na manutenção da integridade corporal do recém-nascido pré-termo. Rev. gaúcha enferm. 1983;4(2): 129-36.

Artigo recebido em 02.04.08.

Aprovado para publicação em 31.03.09. 